\title{
Multiple Keratocysts of the Mandible in Association with Multiple Basal Epithelioma, J aw Cysts and Bifid Rib Syndrome: A Rare Case Report
}

\author{
${ }^{1}$ Gayathri H Kulkarni, ${ }^{2}$ Shahanavaj I Khaji, ${ }^{3}$ Harish S Kulkarni, ${ }^{4}$ S uryakant B Metkari, ${ }^{5}$ Reshma Kulkarni
}

\begin{abstract}
Nevoid basal cell carcinoma syndrome is a syndrome with wide variety of manifestations ranging from oral lesions to skeletal deformities. It calls for due responsibility of maxillofacial surgeon to diagnose the syndrome because very often they are the first health professionals to see the patient for the treatment of keratocystic odontogenic tumor.

Keratocystic odontogenic tumor (KCOT) has been the topic of numerous investigators and is known for its potentially aggressive behavior and significantrate of recurrences. Keratocystic odontogenic tumor often occurs as a solitary lesion, and in some instances multiple keratocysts may occur in association with a syndrome called Gorlin-Goltz syndrome (nevoid basal cell carcinoma, jaw cyst bifid rib basal cell nevus syndrome).

Here, we present a case of multiple keratocysts in the mandible in association with skeletal, ocular and cutaneous anomalies in the given clinical scenario which has profound relevance in the clinical dental practice.
\end{abstract}

Keywords: Syndromic multiple keratocysts, Mandible, Nevi, Gorlin-Goltz syndrome.

How to cite this article: Kulkarni GH, Khaji SI, Kulkarni HS, Metkari SB, Kulkarni R. Multiple Keratocysts of the Mandible in Association with Multiple Basal Epithelioma, J aw Cysts and Bifid R ib Syndrome: A R are Case Report. Int J Head Neck Surg 2014;5(1):39-41.

\section{Source of support $\mathrm{Nil}$}

Conflict of interest None

\section{INTRODUCTION}

The nevoid basal cell carcinoma syndrome, first delineated by Gorlin and Goltz (1960) is characterized by basal cell carcinoma, odontogenic keratocysts, palmar and plantar

\footnotetext{
${ }^{1} \mathrm{P}$ rofessor and $\mathrm{Head},{ }^{2,5}$ S enior Lecturer, ${ }^{3} \mathrm{P}$ rofessor and P rincipal, ${ }^{4}$ Associate Professor

${ }^{1-3,5}$ Department of O ral and Maxillofacial Surgery, Tatyasaheb Kore Dental College and Research Centre, Kolhapur Maharashtra, India

${ }^{4}$ Department of Oral and Maxillofacial Pathology, Tatyasaheb Kore Dental College and Research Centre, Kolhapur Maharashtra, India

Corresponding Author: Shahanavaj I Khaji, Senior Lecturer Department of Oral and Maxillofacial Surgery, Tatyasaheb Kore Dental College and Research Centre, Mahatma Gandhi Hospital Campus, New Pargaon-416137, Kolhapur Maharashtra, India, Phone: +91-8007055163, e-mail: forevershaan@gmail.com
}

pits and ectopic calcification of falx cerebri. ${ }^{1,2}$ Seventy-five percent of patients affected by nevoid basal cell carcinoma syndrome (NBCCS) show multiple and bilateral keratocysts. $M$ ainly located in premolar area may displace teeth with consequent malocclusion. ${ }^{2}$

This syndrome has received several names throughout the times such as 'basal cell nevus syndrome', ' nevoid basal cell carcinomas syndrome' or the most complex name of ' $m u l$ tiple basal epithelioma, jaw cysts and bifid rib syndrome'. ${ }^{3}$

Nevoid basal cell carcinoma syndrome is a rare autosomal dominant condition that can cause unusual facial appearances. The reported prevalence is one case per 56000-164000. ${ }^{1,4}$ Despite the number of cases reported in the literature, the understanding of complete form of NBCCS is not yet conclusive. Besides the fact that the signs and symptoms of NBCCS appear as the patient ages, they do not occur concomitantly; these are challenges to the diagnostician. ${ }^{5}$

The dental clinician may be the first to encounter and identify this syndrome when multiple cysts like radiolucencies are discovered on radiographic examination of the jaws. Due to the importance of oral and maxillofacial manifestations of this syndrome, it is fundamental to know its characteristic in order to make a diagnosis, an early preventive treatment and establish right genetic advice. ${ }^{6}$ This piece of work attempts to highlight the salient features of an unusual case of multiple keratocysts in association with Gorlin-Goltz syndrome with its management.

\section{CASE REPORT}

In A ugust 2012, a 21 years old male reported to the OPD, Department of Oral and M axillofacial Surgery, Tatyasaheb K ore Dental College and Research Centre, Kolhapur, $M$ aharashtra, India, with chief complaint of pain and swelling in the lower left back region of the jaw since 3 to 4 months. The patient had visited a dentist few months ago with the same complaint where removal of 36,37 was advised. Patient was moderately built and well nourished with no history of chewing habits and nonsignificant medical and dental history.

General physical examination revealed bluish black macular pigmentation measuring $0.25 \times 0.75 \mathrm{~cm}$ on forehead 
and periorbital region was evident (Fig. 1). Clinical examination revealed mild facial asymmetry on the left side of face. Intraoral examination showed significant expansion of the buccal cortex, egg shell crackling, overlying swelling was firm in consistency, tender, nonfluctuant and nonpul sative upon palpation.

The patient was subjected for radiographic examination which reveal ed well defined radiolucent areas extending on either sides of mandibular body, angle and ramus region respectively. Significant resorption of the bone was evident on left side in relation to $35,36,37$ region respectively (Fig. 2).

Observing the OPG findings a radiographic diagnosis of multiple keratocystic odontogenic tumors was suggested.

The patient was subjected for fine-needle aspiration cytology (FNAC) and incisional biopsy following the routine blood examination which helped us to arrive to a final diagnosis keratocystic odontogenic tumor in association with Gorlin-Goltz syndrome (Fig. 3). Patient was taken up for surgical enucleation of the cystic lesion on both sides with application of Carnoy's solution onto the defect under general anesthesia ( Figs 4 A and B). Patient was periodically followed up for the recurrence of disease and was monitored for regeneration of the bone defect accordingly.

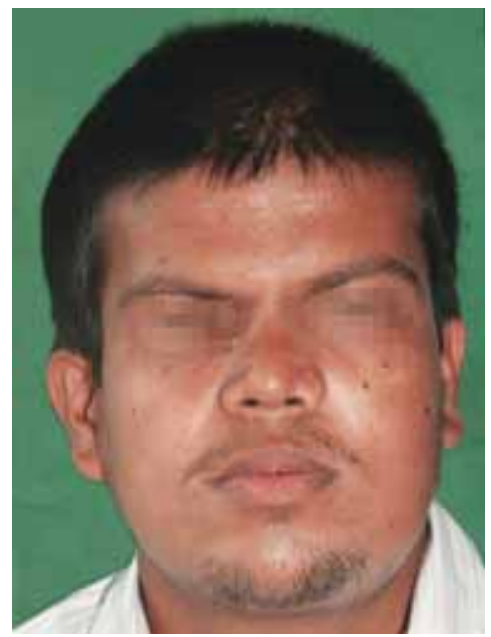

Fig. 1: Skin lesions on the forehead and periorbital region

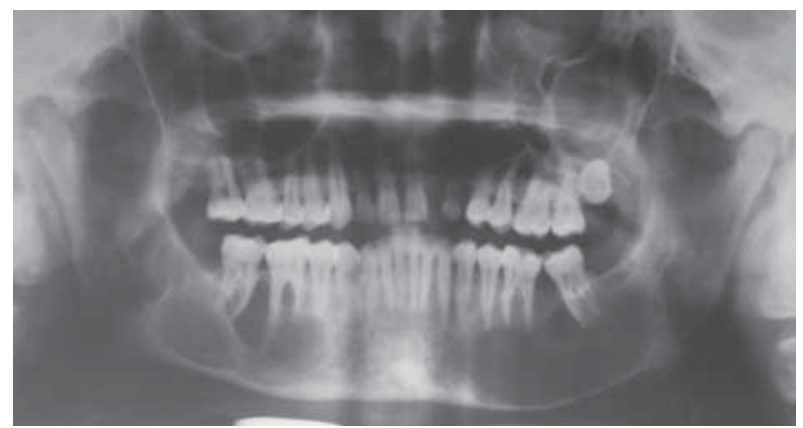

Fig. 2: Panoramic radiograph showing multilocular appearance of the lesion

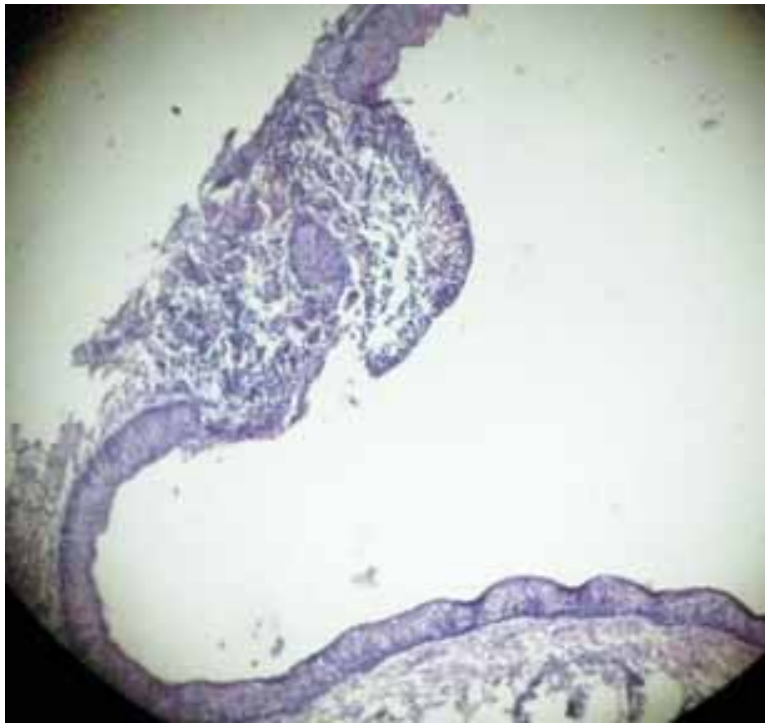

Fig. 3: Photomicrograph showing characteristic lining of keratocystic odontogenic tumor (H\&E stain)

\section{DISCUSSION}

Nevoid basal cell carcinoma syndrome is a rare inherited multisystem disorder that is a result of mutations in the PTCH gene. M ore than 100 clinical abnormalities have been reported in this syndrome. The major criteria are- early development of multiple basal cell cancers (BCCs), odontogenic (bone) keratocysts, palmar and plantar pitting, ectopic intracranial calcification and family history. M inor criteria include craniofacial anomalies (macrocephaly, frontal bossing, hypertelorism), bifid ribs, early onset medulloblastomas, cardiac or ovarian fibromas, lymphomesenteric cysts and congenital malformations (cleft lip/palate, polydactyly, eye abnormalities, colobomas, cataracts and glaucoma). ${ }^{7-9}$

$M$ ajor criteria are as follows:

- More than two BCCs or one under age of 20 years

- Odontogenic keratocyst

- Three or more palmar pits

- Bilamellar calcification of falx cerebri

- Bifid, fused or splayed ribs

- First-degree relative with NBCCS

$M$ inor criteria are as follows:

$M$ acrocephaly adjusted for height:

- Frontal bossing, cleft lip/palate and hypertelorism

- Sprengel deformity, pectus and syndactyly of digits

- B ridging of sella turcica, hemivertebrae and flame shaped

- Radiolucencies

- Ovarian fibroma

- Medulloblastoma

The diagnosis is supported by finding either two major, or one major and two minor criteria. ${ }^{9}$

The odontogenic keratocyst is an epithelial developmental cyst of the jaw. ${ }^{10}$ Some surgeons believe the cyst can be properly treated with enucleation if the lesion is 


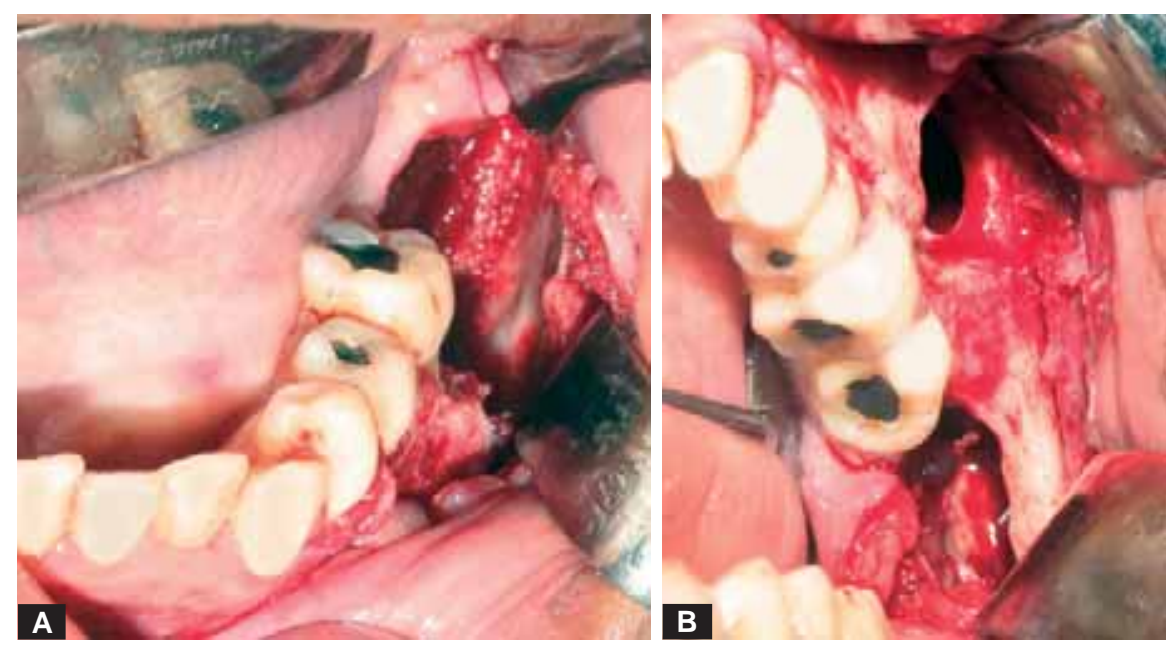

Figs 4 A and B: Intraoperative views of the surgical site

removed intact. ${ }^{11,12}$ However, complete removal of the OKC can be difficult because of the thin friable epithelial lining, limited surgical access, skill and experience of the surgeon, cortical perforation, and the desire to preserve adjacent vital structures. ${ }^{13}$

Less than $10 \%$ of patients with multiple keratocysts have other manifestations of this syndrome; however, it has been suggested that multiple keratocysts al one may be the confirmatory of this syndrome. In the present case, surgical enucleation along with chemical cauterization was done which holds well with the statement that chemical cauterization is a proved adjunctive technique in case of keratocysts and is useful to prevent recurrence by fixing the daughter cysts or remnants of epithelial lining during the enucleation procedure. $^{14}$

\section{CONCLUSION}

It can be said that Gorlin-Goltz syndrome associated with multiple keratocysts is of particular interest for the oral maxillofacial health experts. Thorough clinical examination supplemented with appropriate investigations would reveal the concerned diagnosis as evidenced in the present case. Early diagnosis will often make it possible to use conservative therapies rather than complex treatments. Furthermore, it offers patients and their families the chance of discovering the possible hereditary risks of the condition.

\section{ACKNOWLEDGMENT}

Our sincere thanks to Department of Oral Pathology, for their histopathological expertise, to our staff colleague (Dr Onkar Salokhe) and to all Intern Residents (Dr Omkar M ayekar, Dr Gauri Kulkarni, Dr K etaki J awale, Dr Sagar K adam and DrA njali Karnik) who made this editing work possible otherwise.

\section{REFERENCES}

1. Ramaglia L, M orgese F, Pighetti M, Saviano R. Odontogenic keratocyst and uterus bicornis in nevoid basal cell carcinoma syndrome: case report and review of literature. Oral Surg Oral Med Oral Pathol Oral Radiol Endod 2006;10:217-219.

2. Wood N orman K, Paul W, G oaz. M ultiple separate w ell-defined radiolucencies. Differential diagnosis of oral and maxillofacial lesions. 5th ed. Philadelphia M osby 1997;382-384.

3. Reyes M acais JF, Bagan Sebastian JV. Syndrome de Gorlin-Goltz revision de la literature y reporte de un caso. Rev Europ O donto Estomatol 2002;14(2):105-112.

4. Shear M. The aggressive nature of odontogenic keratocyst. Is it a benign cystic neoplasm? Part 2. Proliferation and genetic studies. Oral Oncol 2002;38:323-331.

5. Vimal K, Nitin K, Geeta K. The syndromic multiple OKC in siblings: A familial study. Ann M axillofac Surg 2011;1(1): 77-82.

6. A itzber OG, Oaltz Garcia A, Sergio ZN, A melia A S. GorlinGolt syndrome: clinicopathologic aspects. Med Oral Pathol Oral Cir Bucal 2008;13(6):E338-343.

7. Howell JB, A nderson DE. The nevoid basal cell carcinoma syndrome. A rch Dermatol 1982;118:813.

8. Lo Muzio Nocini L, Savoia PFA, et al. Nevoid basal cell carcinoma syndrome. Clinical findings in 37 I talian affected individuals. Clin Genet 1999;55:34.

9. Evans DG, L adusans EJ , Rimmer S, et al. Complications of the naevoid basal cell carcinoma syndrome: results of a population based study. J M ed G enet 1993;30:460.

10. M arx RE, Stern D. O ral and maxillofacial pathology: a rationale for diagnosis and treatment. Chicago, IL, Quintessence 2003; 590-601.

11. M ieselman F. Surgical management of the odontogenic keratocyst: conservative approach. J Oral M axillofac Surg 1994;52:960.

12. WilliamsTP, Connor FA. Surgical management of the odontogenic keratocyst: aggressive approach. J Oral M axillofac Surg 1994; 52:964.

13. Teresa A M , Christopher CB, Q ian F. A retrospective review of the treatment of the odontogenic keratocyst. J Oral and $\mathrm{M}$ axillofacial Surgery 2005;63:635-639.

14. Rai S, Gauba K. J aw cyst basal cell nevus-bifid rib syndrome: a case report. J Ind Soc Pedodon Preven Dent 2007;6(Sep):137-139. 